\title{
Parameters of the Wrist Tapping using a Modification of the Original Method (Method of exogenous rhythmic stimulation influence on an individual human rhythm)
}

\author{
Ekaterina A. Narodova, $\mathrm{PhD}^{1^{*}}$; Vyacheslav A. Rudnev, $\mathrm{PhD}, \mathrm{ScD}^{1}$; \\ Natalia A. Shnayder, $\mathrm{PhD}, \mathrm{ScD}^{1,2}$; Valeria V. Narodova, $\mathrm{PhD}, \mathrm{ScD}^{1}$; \\ Evgeniy E. Erakhtin ${ }^{1}$; Diana V. Dmitrenko, $\mathrm{PhD}, \mathrm{ScD}^{1}$; Olga S. Shilkina ${ }^{1}$; \\ Polina V. Moskaleva ${ }^{1}$; Kirill A. Gazenkampf ${ }^{1}$ \\ ${ }^{1}$ V.F. Voino-Yasenetsky Krasnoyarsk State Medical University, Krasnoyarsk, Russia \\ ${ }^{2}$ St. Petersburg V.M. Bekhterev Psychoneurological Research Institute, St. Petersburg, Russia
}

\begin{abstract}
The aim of the present research was to evaluate the main characteristics of tempo-rhythm in healthy adults.

Materials and methods: A total of 33 healthy adult volunteers (20 males and 13 females) participated in the study. The technique involved wrist tapping on the surface of the device (Android smartphone), followed by the registration of the time parameters of this process in the original program based on the modified technique "Method of exogenous rhythmic stimulation influence on an individual human rhythm." The reference boundaries of the wrist tapping characteristics were studied.

Conclusion: The obtained data can be used in neurorehabilitation for patients with a wide range of neurological disorders, including epilepsy. (International Journal of Biomedicine. 2018;8(2):155-158.)
\end{abstract}

Key Words: rehabilitation $\bullet$ wrist tapping $\bullet$ human rhythm $\bullet$ neurology $\bullet$ epilepsy

\section{Introduction}

Tapping is a psychomotor test to assess the psychophysiological brain functions, in particular, the perception of time.(1) Tapping without any external influence, with the patients' preferred speed, is a "biological constant," which reflects the rate of neural processes and endogenous rhythmic processes in the central nervous system. ${ }^{(2)}$ However, during motor reproduction of rhythmic exogenous intervals, the stimulation frequency is important. A number of authors have shown the correlation between the frequency of exogenous stimulation in tapping and the body's reaction. Thus, during stimulation of more than $1 \mathrm{~Hz}$, the leading parameter is the time response, while at the stimulation frequency of less than

*Corresponding author: Ekaterina A. Narodova, PhD. V. F Voino-Yasenetsky Krasnoyarsk State Medical University, Krasnoyarsk, the Russian Federation.E-mail: katyan2001@mail.ru
$1 \mathrm{~Hz}$ it is the stimulus reaction that prevails. Consequently, at $1 \mathrm{~Hz}$ frequency of exogenous stimulation, both reactions have an equivalent value. ${ }^{(3)}$

Despite the long-standing interest in tapping, new developments in this field are constantly emerging due to the fundamental nature of this method. According to V.A. Rudnev, ${ }^{(4)}$ the cycling of movements during carpal tapping is a natural statistical pattern that can be considered as a measurement standard to which different parameters can be compared. Therefore, the study of these biologically reasonable movements allows setting the determination to specific rates and rhythms of movement that occur in cases of pathology at different levels of the human nervous system. This theory paved the way for a large number of dissertations carried out from 1993 to 2014 by the members of the Department of Nervous Diseases of Krasnoyarsk State Medical University. Thus, the functional system "artocinesia" and the functional system "speech" were studied in detail in children with cerebral palsy, ${ }^{(5)}$ acute disorders of cerebral circulation, ${ }^{(6)}$ mild head trauma 
and neurooncological disorders, ${ }^{(7)}$ chronic cerebrovascular pathology, ${ }^{(8)}$ Parkinson's disease and Parkinsonian syndrome, ${ }^{(9)}$ and motor aphasia. ${ }^{(10)}$ The synergy of the wrist tapping was chosen as the object of the study. The study focuses on three parameters that were studied in detail: movement from the tap point - component " $\mathrm{b}$ "; movement to the tap point component "a"; and the time of the full cycle "b+a." (11) Thus, tempo-rhythm correction methods take a special place in neurology and neurorehabilitation..$^{(12)}$

The aim of the present research was to evaluate the main characteristics of tempo-rhythm in healthy adults.

\section{Materials and Methods}

The study was approved by the Ethics Committee of V.F. Voyno-Yasenetsky Krasnoyarsk State Medical University (Protocol № 77/2017 dated 26.06.2017). The study was conducted using a modified original technique "Method of exogenous rhythmic stimulation influence on an individual human rhythm” [RF patent №2606489 dated 10.01.2017].

Modification of the method included carrying out the study of the patients' individual rhythms without the use of exogenous rhythmic stimulation (Fig.1). The study was conducted in the morning with the exclusion of external sensory stimuli (loud sound, bright light) and other people, except the doctor and the volunteer, during the tapping procedure. The temperature regime in the room was maintained in the range of $22^{\circ} \mathrm{C}$ to $25^{\circ} \mathrm{C}$.

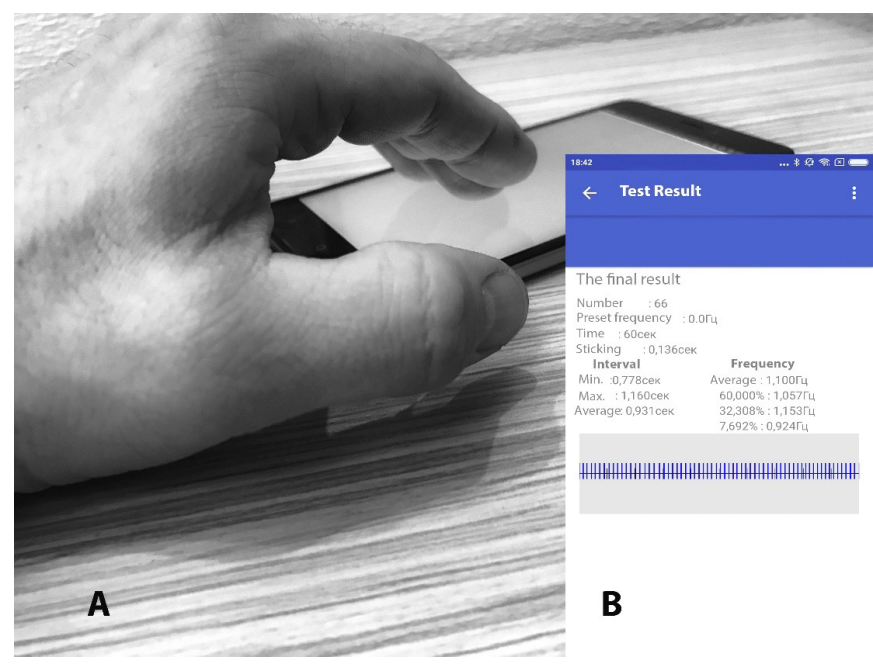

Fig. 1. Method of exogenous rhythmic stimulation influence on an individual human rhythm [RF patent №2606489].

A - General view of the study

B - An example of the results of wrist tapping in healthy volunteer.

\section{Inclusion criteria:}

-Healthy adults

-Signed voluntary informed consent

-Male and female

-The age period: the youth (males 17-21; females 16-
20 years); the first period of middle age (males 22-35 years; females 21-35 years); the second period of middle age (males 36-60 years; females 36-55 years)

-Russian-speaking Europeans

\section{Exclusion criteria:}

-Children and adolescents

-Refusal to participate in this study

-Participation in other studies

-Acute and chronic neurological, psychiatric and endocrinological disorders at the time of examination -Alcohol intake ( 2 or more drinks during the last 2 weeks)

-Index of anxiety level on Beck's hospital scale (0-9 points)

-Use of narcotic drugs at the time of the study and in history

Volunteers did not receive any payment for participating in this study. The researchers did not receive any payment for conducting the study.

\section{Study procedure}

The technique involved wrist tapping on the surface of the device (Android smartphone), followed by the registration of the time parameters of this process in the original program based on the modified technique "Method of exogenous rhythmic stimulation influence on an individual human rhythm."

During the task performance, the mechanogram where vertical strokes display the contact of the finger with the screen appears on the screen of the device. We analyzed the following parameters: total number of taps per minute; average frequency of taps per second $(\mathrm{Hz})$; stability - the proportion of the frequency of taps (in percentage); the delay time of the subsequent tap (in seconds); and the intervals between taps, including the maximum interval (in seconds), the minimum interval (in seconds), and the average interval (in seconds). Also, the registration of an individual "minute" was carried out with a stopwatch. Volunteers were asked to count 60 seconds to themselves, after which they had to say "stop." Time on the stopwatch stopped, the result was recorded.

\section{Participants}

A total of 33 healthy volunteers (20 males and 13 females) participated in the study. The mean age was $33.69 \pm 12.06$ years, the median age was 32 [22; 46.5] years.

\section{Statistical analysis}

Statistical analysis was performed using IBM SPSS Statistics 23. The normality of distribution of continuous variables was tested by one-sample Kolmogorov-Smirnov test. Continuous variables were presented as mean (standard deviation $[\mathrm{SD}]$ ) and as median (interquartile range [IQR]). Means of 2 continuous normally distributed variables were compared by independent samples Student's t test. MannWhitney U test and Kruskal-Wallis test were used, respectively, to compare means of 2 and 3 or more groups of variables not normally distributed. A value of $P<0.05$ was considered significant. 
Table 1.

Tapping parameters in healthy adults

\begin{tabular}{|c|c|c|c|c|c|c|c|}
\hline Parameters & \multicolumn{3}{|c|}{$\mathrm{Me}\left[\mathrm{P}_{25} ; \mathrm{P}_{75}\right]$} & \multicolumn{3}{|c|}{$\mathrm{M} \pm \mathrm{SD}$} & $P$-value \\
\hline $\begin{array}{l}\text { Individual minute, } \\
\text { sec }\end{array}$ & $55[49.25 ; 60.75]$ & $64[58.5 ; 69]$ & $55[49.25 ; 60.75]$ & $56.05 \pm 9.6$ & $63.3 \pm 13.21$ & $56.05 \pm 9.6$ & 0.08 \\
\hline Stability, \% & $64[53.65 ; 71.1]$ & $62.4[56.21 ; 78]$ & $64[53.65 ; 71.16]$ & $64.66 \pm 12.44$ & $66.22 \pm 11.09$ & $64.66 \pm 12.44$ & 0.19 \\
\hline $\begin{array}{l}\text { Dela time of the } \\
\text { subsequent tap, sec }\end{array}$ & $0.11[0.09 ; 0.2]$ & $0.09[0.07 ; 0.19]$ & $0.11[0.09 ; 0.2]$ & $0.15 \pm 0.11$ & $0.11 \pm 0.04$ & $0.15 \pm 0.11$ & 0.5 \\
\hline $\begin{array}{l}\text { Minimum interval } \\
\text { between taps, sec }\end{array}$ & $0.6[0.48 ; 0.73]$ & $0.66[0.63 ; 0.7]$ & $0.6[0.48 ; 0.73]$ & $0.54 \pm 0.24$ & $0.65 \pm 0.08$ & $0.54 \pm 0.24$ & 0.7 \\
\hline $\begin{array}{l}\text { Total number of } \\
\text { taps }\end{array}$ & $66[61.5 ; 72.75]$ & $71[55 ; 74.5]$ & $66[61.5 ; 72.75]$ & $66.8 \pm 7.4$ & $66.84 \pm 9.34$ & $64.66 \pm 12.44$ & 0.9 \\
\hline
\end{tabular}

\section{Results}

The results of the use of the "Method of exogenous rhythmic stimulation influence on an individual human rhythm" to assess the main characteristics of wrist tapping in healthy adults are presented in Table 1.

In healthy young men, the median of individual "minute" was higher than in women of similar age (64 [58.5; 69] seconds against 55 [49.25; 60.75] seconds, respectively), and the average time was $63.3 \pm 13.21$ against $56.05 \pm 9.6$ seconds, respectively. However, gender differences were not statistically significant. The median of individual rhythm in men and women was $1.1 \mathrm{~Hz}$.

We did not find statistically significant differences in maximum and minimum stability, time delay, intervals between taps or total number of taps in the total sample of men and women $(P>0.05)$. Thus, it is possible to neglect gender differences in the group of adult volunteers in the subsequent use of the obtained reference boundaries of the wrist tapping characteristics.

\section{Discussion}

When implementing new rehabilitation techniques, including different variations of wrist tapping, it is important not only to develop software for available means of communication (such as, for example, an Android smartphone), but also to develop and subsequently use the received reference boundaries as a norm. It will allow us to continue research using the original technique "Method of exogenous rhythmic stimulation influence on an individual human rhythm." We plan to use the obtained data in neurorehabilitation for patients with a wide range of neurological disorders, including epilepsy.

\section{Conflict of interest}

The authors declare that they have no conflicts of interest to disclose.

\section{References}

1. Bykov YN. [Cerebral integrated mechanisms (Message 2)]. Siberian Medical Journal (Irkutsk). 2001;(2):4-9. [Article in Russian].

2. Pogelt B, Roth N, Poget A. Automated rhythmic movements and their control under different experimental conditions. Biomed Biochim Acta. 1984;43(4):485-491.

3. Fress P. Perception and time evaluation. Moscow: Progress; 1978. [In Russian].

4. Rudnev VA. Functional diagnostics and restoration of voluntary movements in the pathology of the central nervous system. Krasnoyarsk: Publishing house of Krasnoyarsk University; 1982. [In Russian].

5. Narodova VV. Ontogenetic dynamics of individual rhythm of man. In: Efficiency of sanatorium-and-spa treatment in health resorts of the Krasnoyarsk Territory. Krasnoyarsk; 1991:117-119. [In Russian].

6. Fajzulin ER, Bykov YN. [Rehabilitation in patients with cerebral ischemic stroke in out-patient department]. Siberian Medical Journal (Irkutsk). 2009;(5):20-23. [Article in Russian]. 
7. Narodov AA, Narodova VV. The course of traumatic brain disease in persons with aberrant development. In: Actual questions of craniocerebral trauma and other urgent pathology in injuries and diseases of the nervous system. Krasnoyarsk; 1990:1-3. [In Russian].

8. Prokopenko SV, Rudnev VA, Bugaev AT. [Complex neurorehabilitation in the State Institution «Siberian District Center of the Ministry of Health of Russia»]. Siberian Medical Review. 2005;(1):50-52. [Article in Russian].

9. Pohabov DV. Diagnosis and treatment of walking disorders in Parkinsonism. Abstract of ScD Thesis. Irkutsk; 2009. [In Russian].
10. Narodova EA, Prokopenko SV, Narodova VV, Narodov AA. [Study of inner speech by means of language microarticulation registration in the healthy patients. Journal of New Medical Technologies]. 2012;(4):73-75. [Article in Russian].

11. Prokopenko SV, Rudnev VA. [Krasnoyarsk scientific school of neurorehabilitation]. Siberian Medical Review. 2012;(6):104-106. [Article in Russian].

12. Narodova EA, Shnayder NA, Narodova VV, Dmitrenko DV, Artyukhov IP. The Role of Non-Drug Treatment Methods in the Management of Epilepsy. International Journal of Biomedicine. 2018;8(1):9-14. doi: 10.21103/Article8(1)_BR. 